\title{
Trichoderma Activity in Seed Germination, Promoting Seedling Growth and Rhizocompetence in Tomato Plants
}

\author{
S. C. L. Montalvão ${ }^{1}$, E. Marques ${ }^{2}$, J. B. T. Silva ${ }^{1}$, J. P. Silva ${ }^{1} \&$ S. C. M. Mello ${ }^{1}$ \\ ${ }^{1}$ Embrapa Genetic Resources and Biotechnology, Brasília, Brazil \\ ${ }^{2}$ UPIS Integrated Colleges, Brasília, Brazil \\ Correspondence: S. C. M. Mello, Embrapa Genetic Resources and Biotechnology, Brasília, Brazil. Tel: \\ 55-61-3448-4776. E-mail: sueli.mello@embrapa.br
}

$\begin{array}{lr}\text { Received: July 26, 2020 } & \text { Accepted: August 27, } 2020 \quad \text { Online Published: September 15, } 2020 \\ \text { doi:10.5539/jas.v12n10p252 } & \text { URL: https://doi.org/10.5539/jas.v12n10p252 }\end{array}$

The research is financed by CAPES (Coordination for the Improvement of Higher Education), CNPq (National Council for Scientific and Technological Development) and FAP-DF (Federal District Research Foundation).

\begin{abstract}
Tomato is one of the most important plant species from an economic and social point of view. Nowadays, there is a growing interest in the use of beneficial microorganisms in agriculture, and some of them are being commercialized as biopesticidal and biofertilizer formulations. Therefore, the aim of this study was to evaluate the ability of twenty (20) Trichoderma isolates to stimulate seed germination, colonize the roots, and promoting growth on tomato seedlings. In laboratory tests, it was possible to observe germination induction and longer root length, in addition to greater length of hypocotyls. However, in some cases, the presence of cotyledon lesions in the seedlings was observed, but without interference in the number and vigor of seedlings from inoculated seeds. In the greenhouse, the action of isolates as growth promoters was verified, due to the increase in the weight and length of roots and the aerial part of tomato plants. Twelve isolates were selected for the rhizocompetence assay, in which the ability to colonize the rhizosphere and also the plant rhizoplane was observed. None of the tests showed negative results in the evaluated parameters.
\end{abstract}

Keywords: beneficial effects, biocontrol agents, Lycopersicon esculentum

\section{Introduction}

Tomato (Lycopersicon esculentum Mill.) is one of the most important plant species from an economic and social point of view. Worldwide, more than 4.4 million hectares are cultivated with this garden vegetable. Brazil occupies ninth place in this ranking, with an estimated area of 54.983 hectares occupied with tomato production and a yield of approximately 3.8 million tons (IBGE, 2020).

Nowadays, there is a growing interest in the use of beneficial microorganisms in agriculture, and some of them are being commercialized as biopesticidal and biofertilizer formulations (Zilli et al., 2019). Fungi of the genus Trichoderma are among the most studied, due to their multiple effects on plants, acting as disease biocontrol agents (Harman, 2011) on the growth and development of plants and, also, for their ability to induce defense responses against phytopathogens, insect damage and abiotic stress (Vitti et al., 2015).

Trichoderma comprises a vast number of anamorphic fungi that, at the perfect stage, belong to the genus Hypocrea, family Hypocreaceae (Kirk, 2012). They are widely distributed in the world and can be found as free-living organisms (saprophytes) in soils of natural environments and, equally, in cultivated areas, especially in those rich in organic matter. However, several species of Trichoderma are often isolated from plant tissues, both superficial and internal, and from phytopathogenic fungi structures with which they maintain hyperparasitism relationships. Isolates of these fungi may have the ability to suppress diseases, induce resistance in the host and promote plant growth (Harman, 2011; Sandheep et al., 2013). The effect of Trichoderma spp. in promoting plant development can be observed in the germination of the seeds, rooting, sprouting of cuttings, growth of branches, increase of leaf area, delay in senescence, accumulation of organic matter (fresh and dry mass) and increase in crop yield (Mastouri et al., 2010; Azarmi et al., 2011; Ethur et al., 2012; Sandheep et al. 2013; Hajieghrari \& Mohammadi, 2016; Islam et al., 2016; Uddin et al., 2018). 
According to Stewart and Hill (2014), Trichoderma interactions in microhabitats vary between isolates, that is, intraspecifically and according to the species of plant involved. Druzhinina et al. (2011) corroborate this idea by saying that the effect of Trichoderma in association with plant roots can be neutral, pathogenic or beneficial.

In view of the above, this study aimed to evaluate the effect of Trichoderma spp. on germination of seeds, and rhizocompetence as well as growth promoters in tomato seedlings.

\section{Method}

\subsection{Fungal Isolates}

The work was carried out in the Laboratory of Phytopathology, of the Biological Control Building, Embrapa Genetic Resources and Biotechnology (CENARGEN). Twenty (20) Trichoderma isolates were used (Table 1).

Table 1. Description of the Trichoderma isolates used in this study

\begin{tabular}{llll}
\hline Embrapa Collection Code & Species & Crop/substrate of origin & Collection location \\
\hline CEN141 & Trichoderma sp. & Soybeen & Orizona-GO \\
CEN155 & T. afroharzianum & Mayze & Orizona-GO \\
CEN161 & T. asperellum & Rice & Goianira-GO \\
CEN162 & T. asperelloides & Rice & Goianira-GO \\
CEN201 & Trichoderma sp. & Vochysiaceae & Goiatins/Itacará-MT \\
CEN219 & Trichoderma sp. & - & - \\
CEN273 & Trichoderma sp. & Cotton & Rio Preto-DF \\
CEN281 & T. afroharzianum & Cotton & Rio Preto-DF \\
CEN287 & T. afroharzianum & Cotton & Rio Preto-DF \\
CEN289 & T. afroharzianum & Cotton & Rio Preto-DF \\
CEN1071 & T. brevicompactum & Tomato & CNPH-DF \\
CEN1072 & Trichoderma sp. & Tomato & CNPH-DF \\
CEN1073 & Trichoderma sp. & Tomato & CNPH-DF \\
CEN1074 & T. brevicompactum & Tomato & CNPH-DF \\
CEN1075 & T. asperellum & Tomato & CNPH-DF \\
CEN1076 & Trichoderma sp. & Tomato & CNPH-DF \\
CEN1077 & Trichoderma sp. & Tomato & CNPH-DF \\
CEN1078 & Trichoderma sp. & Tomato & CNPH-DF \\
CEN1079 & Trichoderma sp. & Tomato & CNPH-DF \\
CEN1080 & Trichoderma sp. & Tomato & CNPH-DF \\
\hline
\end{tabular}

Note. ${ }^{*}$ Commercial product.

\subsection{Effect of Trichoderma Isolates on Seed Germination and Tomato Seedling Development}

Italian type 'San Vito' tomato seeds were inoculated with Trichoderma spp. by immersion in conidia suspension for 24 hours. The suspensions, containing $6 \times 10^{8}$ conidia $\mathrm{mL}^{-1}$, were obtained from cultures of the fungus grown in PDA medium, at $25{ }^{\circ} \mathrm{C}\left( \pm 2{ }^{\circ} \mathrm{C}\right)$, with constant light for seven days. After inoculation, the seeds were sown in gerboxes lined with two sheets of filter paper moistened with sterile distilled water. As control treatement, boxes were prepared with seeds immersed in water. Twenty-five tomato seeds were distributed per box and these were kept at a temperature of $25^{\circ} \mathrm{C}\left( \pm 2{ }^{\circ} \mathrm{C}\right)$. The filter paper was daily moistened with sterile distilled water and, after 72 hours, the number of germinated and non-germinated seeds was determined. At 10 days, the number of seeds with normal germination, abnormal germination and number of dead seeds were determined, also measuring the radicle and hypocotyl length. All seedlings that presented the rotten, damaged hypocotyl and absence of hypocotyl or absence of the primary root were considered as abnormal germination (Nakagawa, 1999).

A completely randomized design was used, with three replications per treatment, each experimental unit consisting of a gerbox ( 25 seeds).

\subsection{Promotion of Tomato Growth by Trichoderma Isolates}

The experiment was carried out in a greenhouse, where the humidity remained at 70 to $80 \%$ and the temperature ranged from 23 to $40{ }^{\circ} \mathrm{C}$, with a 12-hour photoperiod. Pots containing $500 \mathrm{~mL}$ filled with autoclaved soil were used. On the soil surface, $25 \mathrm{~mL}$ of $6 \times 10^{7}$ conidia $\mathrm{mL}^{-1}$ Trichoderma suspension was sprayed. Eight Italian 'San Vito' tomato seeds were deposited in each pot after the fungus had been applied. Twenty Trichoderma isolates 
were used. Fourteen days after seedling emergence, measurements of root length, aerial part and dry weight of plant roots were obtained. To obtain the dry root weight, they were dried in an oven, at a temperature of $60{ }^{\circ} \mathrm{C}$, until they reached constant weight (approximately 72 hours). The treatment control consisted of pots containing soil not treated with Trichoderma.

A completely randomized design was adopted, each experimental unit consisting of a pot with eight plants. The experiment was conducted three times, with three replicates per treatment.

\subsection{Evaluation of Trichoderma Isolates for Tomato Rhizocompetence}

The Trichoderma isolates that performed better in growth promotion experiments were evaluated for rhizocompetence in a greenhouse, under the same conditions described above. Italian 'San Vito' tomato seeds were superficially sterilized with sodium hypochlorite solution $(5 \%)$, washed twice with sterile distilled water and then submerged in conidial suspension $\left(5 \times 10^{8}\right.$ conidia $\left.\mathrm{mL}^{-1}\right)$ for a period of 24 hours, for their adhesion to the seed surface. To compose the treatment control, tomato seeds were treated identically, but immersed in sterile distilled water without the presence of Trichoderma conidia. Ten seeds were sown per pot, for each treatment with Trichoderma. After two weeks under these conditions, the roots of the seedlings were removed from the soil, shaken to remove loosely adhered soil and cut into fragments using a sterile scalpel. The root fragments with strongly adhered soil were air dried and weighed. For sampling the rhizosphere microflora, $1 \mathrm{~g}$ of root was taken to a sterile environment and kept in test tubes containing $9 \mathrm{~mL}$ of sterile $0.05 \%$ Tween 80 solution, under agitation in an ultrasonic device for two minutes. After stirring, the suspension was subjected to serial dilutions according to the modified Dhingra and Sinclair (1985) methodology, obtaining suspensions with dilutions of $10^{-2}$ $10^{-3}$ and $10^{-4}$. Aliquots of $100 \mu \mathrm{L}$ of these diluted suspensions were spread using a Drigalski loop, in Martin's medium (semi-selective for Trichoderma). For each isolate, nine plates were prepared, which were sealed with plastic film and kept in the incubator at $25^{\circ} \mathrm{C}\left( \pm 2{ }^{\circ} \mathrm{C}\right)$ in the absence of light, for three days. After this period, the plates were transferred to another incubator, maintained in the same conditions as the surpacitated ones, but with a 12-hour photoperiod. To sample the rhizoplane, the root segments were washed with running tap water and, after drying in air, serial dilutions and plating were performed as in the previous treatment.

The greenhouse experiment was conducted three times, in a completely randomized design, each experimental unit consisting of a pot with eight plants. In the plating, a plate was made by dilution, in each treatment.

\subsection{Statistical Analysis}

To perform the statistical analysis of the tests presented here, the Silhouette validation method was used (Rousseeuw, 1987), with the help of the R Program, whose construction is given by:

$$
S(i)=\frac{b(i)-a(i)}{\max \{a(i), b(i)\}}
$$

where, $(i)$ is the average dissimilarity of object $i$ in relation to all other objects in the same cluster; $b(i)$ is the minimum mean dissimilarity of object $i$ in relation to all other clusters (in the closest cluster); then the formula -1 $\leq S(i) \leq 1$ was applied.

It is assumed that the Silhouette length for each sample is calculated, the average Silhouette width for each cluster, the global Silhouette average and the average for the total data set. With this approach, each cluster can be represented by the so-called Silhouette, based on the comparison of its narrowing and separation. The average Silhouette length was applied for cluster validation and also to decide the ideal number of clusters.

According to this method, if the Silhouette value is close to 1, it means that the sample is well clustered and has been assigned to an appropriate cluster. If the value of the Silhouette is close to zero, it means that the sample could be assigned to another closer cluster, and the sample is equally distant from both clusters. If the Silhouette value is -1 , it means that the sample was wrongly classified. The average length of the Silhouette for all objects is simply the average of $S(i)$.

\section{Results and Discussion}

\subsection{Effect of Trichoderma spp. on Seed Germination and Root Length of Tomato Seedlings}

The studied Trichoderma isolates were divided into four clusters (groups) based on the statistical method used (Table 2). In group 3 are the isolates with the best seed germination rate: CEN161, CEN281 and CEN1075. Next, group 1 is presented, with isolates: CEN1071, CEN1072, CEN287, CEN219, CEN1073 and group 3 (Control), with isolates CEN1074, CEN1078, CEN155, CEN1070 and CEN1079. Then, there is group 2 with the isolates: CEN201, CEN1080, CEN273, CEN1077, CEN1076 and CEN289 and, finally, group 4 which had the lowest germination rates and is made up of CEN162 alone. It is also noted that groups 2 and 4 (which together comprise 
8 isolates) had lower germination rates than the control values and, therefore, have a negative effect on the number of germinated tomato seeds.

Table 2. Grouping of Trichoderma isolates based on the germination test and root length of tomato seeds treated with the fungus, based on the avarage length method of the Silhouette

\begin{tabular}{|c|c|c|c|c|c|c|}
\hline \multirow{2}{*}{ Strain } & \multicolumn{3}{|c|}{ Germination } & \multicolumn{3}{|c|}{ Radicle length } \\
\hline & Group & Number of germinated plants & Silhouette Validation & Group & Length in $\mathrm{cm}$ & Silhouette Validation \\
\hline CEN1070 & 1 & $21.7 \pm 3.48^{*}$ & 0.85 & 1 & $8.28 \pm 0.97^{*}$ & 0.63 \\
\hline CEN1071 & 1 & $21.7 \pm 3.48$ & 0.66 & 2 & $8.48 \pm 0.74$ & 0.78 \\
\hline CEN1072 & 1 & $21.7 \pm 3.48$ & 0.85 & 2 & $8.48 \pm 0.74$ & 0.78 \\
\hline CEN1073 & 1 & $21.7 \pm 3.48$ & 0.85 & 6 & $7.86 \pm 1.08$ & 0.75 \\
\hline CEN1074 & 1 & $21.7 \pm 3.48$ & 0.85 & 7 & $7.20 \pm 0.63$ & 0.68 \\
\hline CEN1075 & 3 & $22.6 \pm 3.20$ & 0.75 & 3 & $8.96 \pm 1.39$ & 0.34 \\
\hline CEN1076 & 2 & $21.0 \pm 4.00$ & 0.56 & 7 & $7.20 \pm 0.63$ & 0.68 \\
\hline CEN1077 & 2 & $21.0 \pm 4.00$ & 0.56 & 4 & $6.51 \pm 0.55$ & 0.92 \\
\hline CEN1078 & 1 & $21.7 \pm 3.48$ & 0.85 & 8 & $6.84 \pm 0.88$ & 0.87 \\
\hline CEN1079 & 1 & $21.7 \pm 3.48$ & 0.85 & 8 & $6.84 \pm 0.88$ & 0.87 \\
\hline CEN1080 & 2 & $21.0 \pm 4.00$ & 0.56 & 1 & $8.28 \pm 0.97$ & 0.63 \\
\hline CEN155 & 1 & $21.7 \pm 3.48$ & 0.85 & 4 & $6.51 \pm 0.55$ & 0.92 \\
\hline CEN161 & 3 & $22.6 \pm 3.20$ & 0.75 & 5 & $7.56 \pm 0.56$ & 0.56 \\
\hline CEN162 & 4 & $19.9 \pm 4.38$ & 0 & 6 & $7.86 \pm 1.08$ & 0.75 \\
\hline CEN201 & 2 & $21.0 \pm 4.00$ & 0.56 & 7 & $7.20 \pm 0.63$ & 0.68 \\
\hline CEN219 & 1 & $21.7 \pm 3.48$ & 0.85 & 8 & $6.84 \pm 0.88$ & 0.87 \\
\hline CEN273 & 2 & $21.0 \pm 4.00$ & 0.56 & 2 & $8.48 \pm 0.74$ & 0.78 \\
\hline CEN281 & 3 & $22.6 \pm 3.20$ & 0.75 & 1 & $8.28 \pm 0.97$ & 0.63 \\
\hline CEN287 & 1 & $21.7 \pm 3.48$ & 0.85 & 5 & $7.56 \pm 0.56$ & 0.56 \\
\hline CEN289 & 2 & $21.0 \pm 4.00$ & 0.56 & 3 & $8.96 \pm 1.39$ & 0.34 \\
\hline Testemunha & 1 & $21.7 \pm 3.48$ & 0.85 & 5 & $7.56 \pm 0.56$ & 0.56 \\
\hline
\end{tabular}

Note. * Mean and standard deviation.

For each of the groups indicated above, the interference of time in germination was studied, that is, the average time that these isolates would take to reach the maximum germination, based on the maximum germination rate of each group. When analyzing Figure 1 with this foundation, it is noted that group 3 was the one that reached the highest number of germinated seeds. In contrast, it presented the longest germination time; group 1 presented both the second highest number of germinated seeds and the second best germination time; group 2, despite being in third place in number of germinated seeds, presented the best germination time; last on the scale of germinated seeds, there is group 4 , also with the third best germination time. 


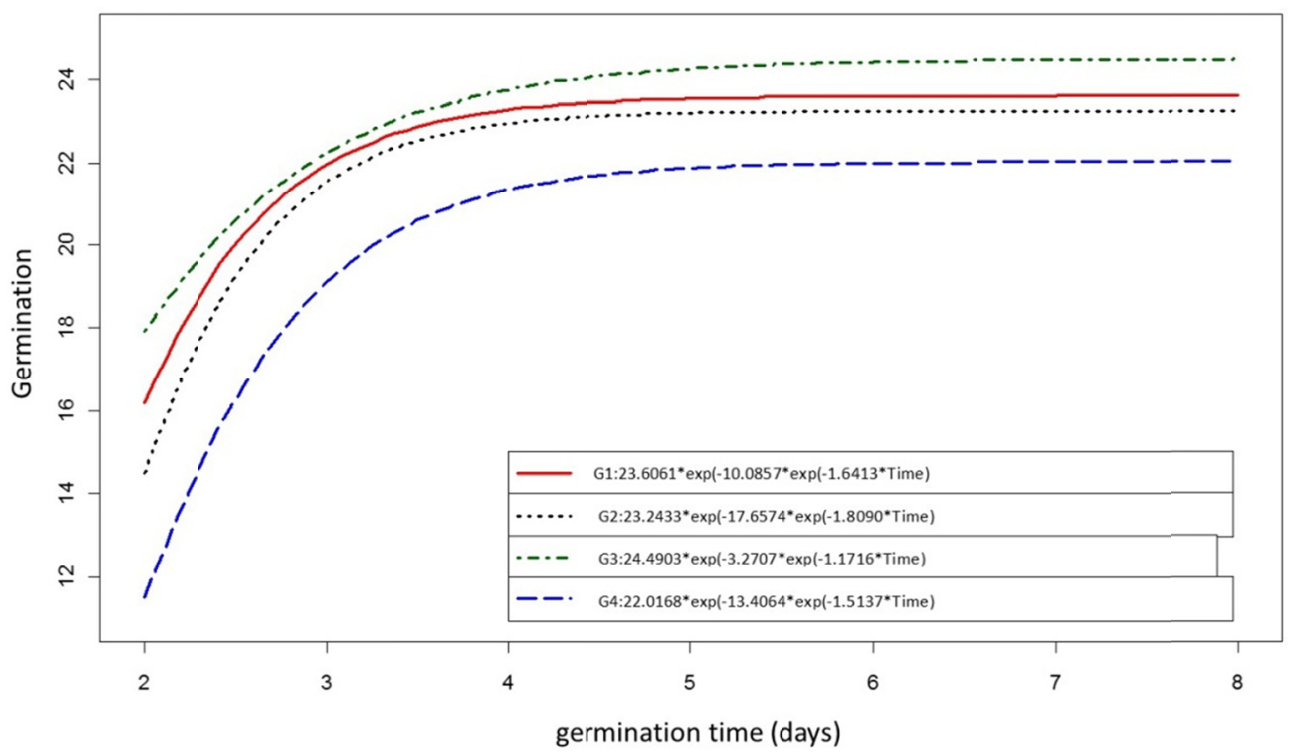

Figure 1. Relationship between the germination of tomato seeds treated with Trichoderma spp. and time in days, according to the non-linear Gompertz model

One of the problems when treating seeds with microorganisms is that certain isolates can occasionally affect germination. Bennett et al. (2009) observed improvement in the germination of carrot and onion seeds treated with $T$. harzianum and $T$. viride, in one experiment, but in the other, the effect was deleterious. According to Ethur et al. (2006), a biological product based on Trichoderma sp. did not interfere with the emergence speed of turnip, black oats and cultivated rye. On the other hand, Mastouri et al. (2010) observed that tomato seeds treated with T. harzianum germinated faster and more uniformly. However, Ethur et al. (2012) reported a negative effect with some isolates of $T$. asperellum, while others had no effect on the germination of cucumber seeds. Azarmi et al. (2011) found no influence on the germination of tomato seeds with T. harzianum and Trichoderma sp. Islam et al. (2011) observed that $T$. harzianum and T. virens led to better germination of chilli seeds. Islam et al. (2016) reported that treatment with $T$. harzianum led to a higher percentage of tomato seed germination. According to Hajieghrari and Mohammadi (2016), this same species provided greater germination of wheat seeds. In this work, the percentage of normal germination was higher than that of abnormal germination and dead seeds; therefore, the isolates evaluated did not cause damage to the seeds when compared to the control, and the use of some of these could become possible in the treatment of tomato seeds.

Regarding the size of the roots and based on the Silhouette length method, eight groups of isolates were formed, as shown in Table 2. The average Silhouette length was 0.68 , respecting the minimum for a good separation of the groups of isolates. The group that showed the greatest root growth was group 3, consisting of the isolates CEN1075 and CEN289; then, in descending order of average root length: group 2 (CEN1071, CEN273 and CEN1072); group 1 (CEN281, CEN1080 and CEN1070); group 6 (CEN1073 and CEN162); group 5 (CEN287, CEN161 and Control); group 7 (CEN1074, CEN201 and CEN1076); group 8 (CEN219, CEN1079 and CEN1078); finally, group 4 (CEN155 and CEN1077) has the shortest root length.

When evaluating the radicle length, it was observed that seeds treated with isolates from groups 3, 2, 1, 6 and 5 were better than or did not differ statistically from the control treatments (Table 2), showing satisfactory root development. According to work by Mastouri et al. (2010), tomato seeds treated with T. harzianum showed greater length of hypocotyl. Different results were obtained in a study carried out by Ethur et al. (2012), when evaluating the development of cucumber seedlings. According to these authors, some isolates of T. asperellum negatively influenced the development not only of the radicle, but also of the hypocotyl of this plant. In contrast, Elias et al. (2016) observed that in treatments with Trichoderma sp. the length of both the radicle and the hypocotyl increased. In this work, the root development of seedlings was shown to be greater than the development of the hypocotyl in all treatments, showing greater induction in root growth. This fact can be justified by the possible effect of Trichoderma isolates through the production of growth regulators such as jasmonates, which can act on seed germination and or on the development of roots (Baker \& Cook, 1974). 


\subsection{Effect of Trichoderma spp. on the Hypocotyl of Tomato Seedlings}

For the effect of Trichoderma isolates on the length of the hypocotyl and based on the Silhouette length method, five groups were formed, as shown in Table 3. The average Silhouette length was 0.73 , which indicates a good separation from the groups of isolates. In group 1, there are the isolates CEN1071 and CEN1070, which provided greater length of hypocotyl, followed by group 5 (CEN289, CEN1075, CEN1078, CEN1074, CEN1080 and CEN1077), group 4 (CEN155, Control, CEN287, CEN281, CEN1079 and CEN219), group 3 (CEN273, CEN1073, CEN161, CEN1072, CEN1076 and CEN201) and, finally, group 2 (CEN162) whose seedlings showed shorter length of hypocotyl. The treatment with isolates belonging to groups 1,5 and 4 showed higher mean lengths of the hypocotyl, differing significantly from all other treatments (Table 3).

Table 3. Grouping of Trichoderma isolates regarding the length of the hypocotyl of tomato seedlings and the number of tomato seedlings with lesions, originating from seeds treated with the fungus, based on the avarage length method of the Silhouette

\begin{tabular}{|c|c|c|c|c|c|c|}
\hline \multirow{2}{*}{ Strain } & \multicolumn{3}{|c|}{ Hypocotyl length } & \multicolumn{3}{|c|}{ Lesion } \\
\hline & Group & Length in $\mathrm{cm}$ & Silhouette Validation & Group & Number of plants with injury & Silhouette Validation \\
\hline CEN1070 & 1 & $4.21 \pm 0.31 *$ & 0.74 & 1 & $4.83 \pm 0.75^{*}$ & 0.25 \\
\hline CEN1071 & 1 & $4.21 \pm 0.31$ & 0.74 & 2 & $8.00 \pm 1.51$ & 0.76 \\
\hline CEN1072 & 3 & $3.40 \pm 0.27$ & 0.75 & 7 & $4.00 \pm 1.79$ & 1 \\
\hline CEN1073 & 3 & $3.40 \pm 0.27$ & 0.75 & 8 & $6.83 \pm 2.23$ & 0.65 \\
\hline CEN1074 & 5 & $3.74 \pm 0.22$ & 0.58 & 3 & $5.33 \pm 1.44$ & 1 \\
\hline CEN1075 & 5 & $3.74 \pm 0.22$ & 0.58 & 6 & $5.75 \pm 2.86$ & 0.63 \\
\hline CEN1076 & 3 & $3.40 \pm 0.27$ & 0.75 & 5 & $3.67 \pm 2.58$ & 1 \\
\hline CEN1077 & 5 & $3.74 \pm 0.22$ & 0.58 & 6 & $5.75 \pm 2.86$ & 0.63 \\
\hline CEN1079 & 4 & $3.56 \pm 0.19$ & 0.79 & 2 & $8.00 \pm 1.51$ & 0.76 \\
\hline CEN1078 & 5 & $3.74 \pm 0.22$ & 0.58 & 6 & $5.75 \pm 2.86$ & 0.63 \\
\hline CEN1080 & 5 & $3.74 \pm 0.22$ & 0.58 & 3 & $5.33 \pm 1.44$ & 1 \\
\hline CEN155 & 4 & $3.56 \pm 0.19$ & 0.79 & 4 & $2.33 \pm 0.58$ & 0 \\
\hline CEN161 & 3 & $3.40 \pm 0.27$ & 0.75 & 5 & $3.67 \pm 2.758$ & 1 \\
\hline CEN162 & 2 & $3.22 \pm 0.46$ & 0.96 & 6 & $5.75 \pm 2.86$ & 0.63 \\
\hline CEN201 & 3 & $3.40 \pm 0.27$ & 0.75 & 2 & $8.00 \pm 1.51$ & 0.76 \\
\hline CEN219 & 4 & $3.56 \pm 0.19$ & 0.79 & 2 & $8.00 \pm 1.51$ & 0.76 \\
\hline CEN273 & 3 & $3.40 \pm 0.27$ & 0.75 & 3 & $5.33 \pm 1.44$ & 1 \\
\hline CEN281 & 4 & $3.56 \pm 0.19$ & 0.79 & 8 & $6.83 \pm 2.23$ & 0.65 \\
\hline CEN287 & 4 & $3.56 \pm 0.19$ & 0.79 & 2 & $8.00 \pm 1.51$ & 0.76 \\
\hline CEN289 & 5 & $3.74 \pm 0.22$ & 0.58 & 1 & $4.83 \pm 0.75$ & 0.25 \\
\hline Control & 4 & $3.56 \pm 0.19$ & 0.79 & 7 & $4.00 \pm 1.79$ & 1 \\
\hline
\end{tabular}

Note. * Mean and standard deviation.

Variable results are reported in the literature, indicating that seed treatment with Trichoderma spp. can exert a positive or negative influence on the germination or development of seedling hypocotyls, as previously mentioned. Positive results may be related to factors such as hormone production, availability of nutrients from the soil or organic matter and increased mineral uptake or translocation (Kleifeld \& Chet, 1992).

According to the lesions observed in the hypocotyl (Figure 2) and analysis by the Silhouette length method, the isolates were separated into eight distinct groups, as shown in Table 3. The average Silhouette length was 0.7, indicating a good separation of the groups of isolates. The group of isolates that presented the lowest index of plants with lesions was group 4, represented by the isolate CEN126, and in sequence, in an increasing number of plants with lesions, there were: group 4 (CEN155); group 5 (CEN161 and CEN1076); group 7 (CEN1072 and Control); group 1 (CEN1070 and CEN289); group 3 (CEN1074, CEN1079 and CEN273); group 6 (CEN162, CEN1075, CEN1080 and CEN1077); group 8 (CEN281 and CEN1073) and, finally, with the largest number of injured plants, group 2 (CEN201, CEN219, CEN1078, CEN287 and CEN1071). 


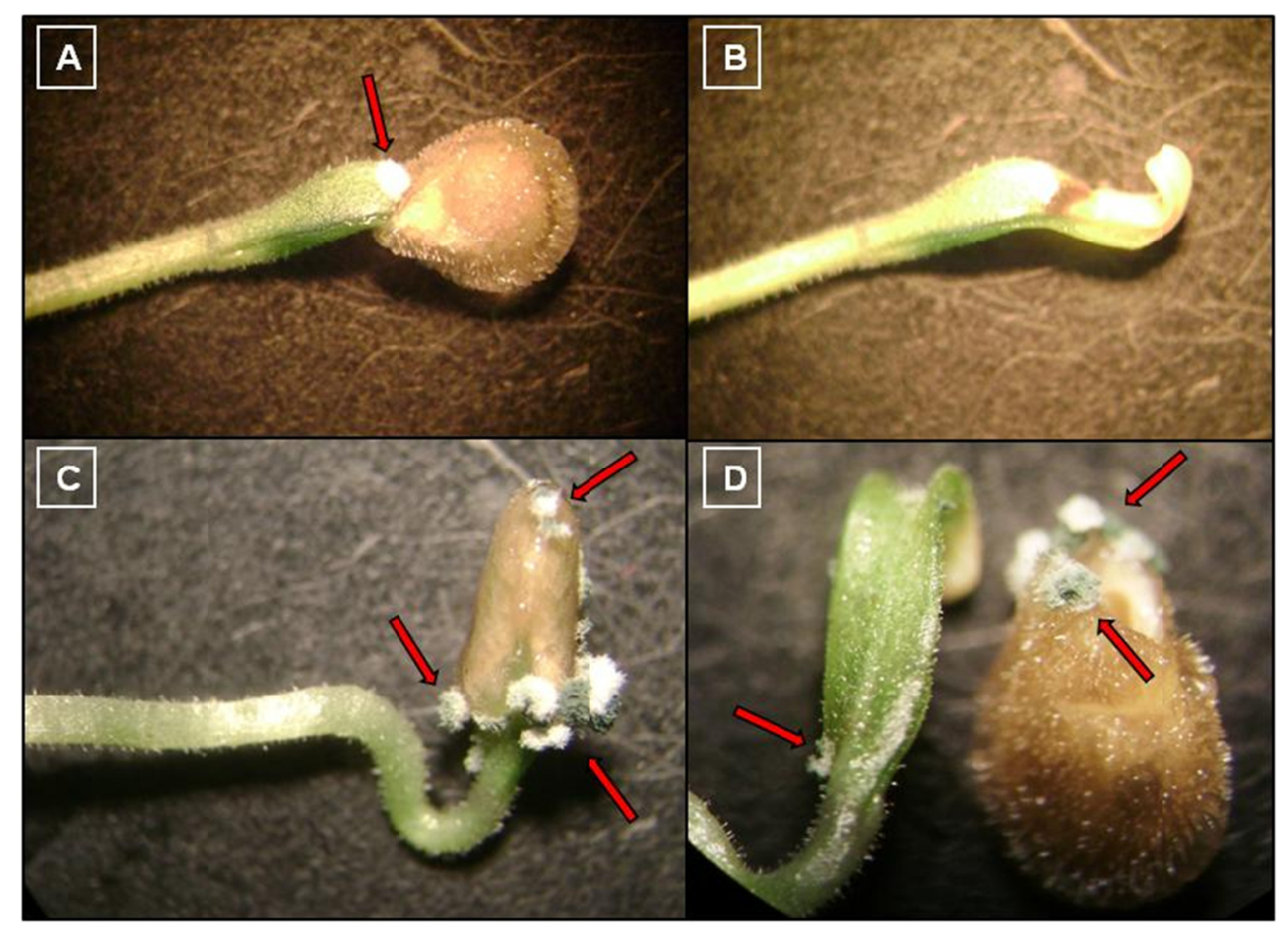

Figure 2. A and C: Germinated tomato seeds, showing tegument colonized by Trichoderma spp.; B: Tomato seedling of image ' $\mathrm{A}$ ' where the seed coat was removed, showing injured cotyledons and D: Tomato seedling of image ' $\mathrm{C}$ ' with a small fragment of colony of Trichoderma spp. at the base of the cotyledon and tegument on the side, colonized by Trichoderma spp.

The variability between Trichoderma spp. regarding interference in the growth of vegetables mainly consists of the production of secondary metabolites and their ability to be competitive in the rhizosphere. Ousley et al. (1993) demonstrated this variability when they used a viridiol-producing Trichoderma isolate that negatively interfered with lettuce germination and other fatty acid and glycerol isolates that acted positively on wheat growth. In addition to the variability between Trichoderma spp. isolates, differences in their action can also be found, depending on temperature, humidity and soil type. Additionally, some Trichoderma isolates have already been reported as pathogenic to some plants (Menzies, 1993; Hajieghrari, 2010; Hajieghrari \& Mohammadi, 2016), but this was not the case in the present study, since no negative effect was found on seedlings of tomato. A factor that can explain the lesions' development is high humidity, in addition to the absence of organic substrate for the growth of the fungus in laboratory conditions, where there was only filter paper and tomato seedlings.

\subsection{Promotion of Tomato Growth in a Greenhouse}

As for the length of the roots, the Trichoderma isolates were grouped into two distinct groups, as shown in Table 4. The average Silhouette length was 0.59 , indicating a good separation of the isolate groups. The highest mean root length values were presented by group 1 (CEN1074, CEN1071, CEN161, CEN1070, CEN1078, CEN281, CEN1075, CEN289 and CEN1077). Group 2 isolates (CEN1072, CEN287, CEN201, CEN219, CEN 162, CEN155, CEN1080, Control, CEN1079, CEN 126, CEN1076 and CEN1073) did not induce root growth; however, there were no statistically inferior results to those verified with the control treatement, so it was inferred that the isolates tested here did not harm the development of the treated roots. 
Table 4. Grouping of Trichoderma isolates in terms of root length and shoot length of tomato seedlings, resulting from seeds treated with the fungus, based on the avarage length method of the Silhouette

\begin{tabular}{|c|c|c|c|c|c|c|}
\hline \multirow{2}{*}{ Strain } & \multicolumn{3}{|c|}{ Root length } & \multicolumn{3}{|c|}{ Shoot length } \\
\hline & Group & Length in $\mathrm{cm}$ & Silhouette Validation & Group & Length in $\mathrm{cm}$ & Silhouette Validation \\
\hline CEN1070 & 1 & $34.8 \pm 5.62 *$ & 0.59 & 1 & $3.94 \pm 0.44 *$ & 0.6 \\
\hline CEN1071 & 1 & $34.8 \pm 5.62$ & 0.59 & 1 & $3.94 \pm 0.44$ & 0.6 \\
\hline CEN1072 & 2 & $28.5 \pm 3.48$ & 0.59 & 4 & $4.90 \pm 1.33$ & 0.83 \\
\hline CEN1073 & 2 & $28.5 \pm 3.48$ & 0.59 & 1 & $3.94 \pm 0.44$ & 0.6 \\
\hline CEN1074 & 1 & $34.8 \pm 5.62$ & 0.59 & 6 & $3.67 \pm 0.24$ & 0.87 \\
\hline CEN1075 & 1 & $34.8 \pm 5.62$ & 0.59 & 5 & $3.23 \pm 0.46$ & 1 \\
\hline CEN1076 & 2 & $28.5 \pm 3.48$ & 0.59 & 2 & $4.20 \pm 0.56$ & 0.56 \\
\hline CEN1077 & 1 & $34.8 \pm 5.62$ & 0.59 & 3 & $3.81 \pm 0.40$ & 0.81 \\
\hline CEN1078 & 1 & $34.8 \pm 5.62$ & 0.59 & 1 & $3.94 \pm 0.44$ & 0.6 \\
\hline CEN1079 & 2 & $28.5 \pm 3.48$ & 0.59 & 2 & $4.20 \pm 0.56$ & 0.56 \\
\hline CEN1080 & 2 & $28.5 \pm 3.48$ & 0.59 & 4 & $4.90 \pm 1.33$ & 0.83 \\
\hline CEN155 & 2 & $28.5 \pm 3.48$ & 0.59 & 4 & $4.90 \pm 1.33$ & 0.83 \\
\hline CEN161 & 1 & $34.8 \pm 5.62$ & 0.59 & 5 & $3.23 \pm 0.46$ & 1 \\
\hline CEN162 & 2 & $28.5 \pm 3.48$ & 0.59 & 6 & $3.67 \pm 0.24$ & 0.87 \\
\hline CEN201 & 2 & $28.5 \pm 3.48$ & 0.59 & 2 & $4.20 \pm 0.56$ & 0.56 \\
\hline CEN219 & 2 & $28.5 \pm 3.48$ & 0.59 & 2 & $4.20 \pm 0.56$ & 0.56 \\
\hline CEN281 & 1 & $34.8 \pm 5.62$ & 0.59 & 4 & $4.90 \pm 1.33$ & 0.83 \\
\hline CEN287 & 2 & $28.5 \pm 3.48$ & 0.59 & 6 & $3.67 \pm 0.24$ & 0.87 \\
\hline CEN289 & 1 & $34.8 \pm 5.62$ & 0.59 & 6 & $3.67 \pm 0.24$ & 0.87 \\
\hline Testemunha & 2 & $28.5 \pm 3.48$ & 0.59 & 3 & $3.81 \pm 0.40$ & 0.81 \\
\hline
\end{tabular}

Note. * Mean and standard deviation.

As for the length of the aerial part, the isolates were divided into six distinct groups (Table 4), where the best results were achieved with the isolates of group 4 (CEN1072, CEN155, CEN281 and CEN1080), followed by: group 2 (CEN219, CEN126, CEN1076, CEN201 and CEN1079); group 1 (CEN1070, CEN1073, CEN1078 and CEN1071); group 3 (CEN1077 and control treatment); group 6 (CEN1074, CEN287, CEN289 and CEN162) and finally, group 5 (CEN161 and CEN1075). There was less growth of hypocotyl with the isolates of groups 6 and 5 , when compared to group 3. However, this difference in the growth of hypocotyl as a variable must be carefully considered, since some of the isolates that showed lower yield in promoting growth of the aerial part provided good results of root growth, as in the case of isolates CEN161, CEN289, CEN1074 and CEN1075, being thus allocated to the first group of the previous test (Table 4). When comparing the dry weight of the root, the Silhouette length analysis showed that the best results for this test were achieved with Trichoderma isolates from groups 3 (CEN155 and CEN1080) and 1 (CEN1072, CEN1070, CEN281, CEN1076, CEN1077, CEN219 and CEN201). The isolates CEN287, CEN1078, CEN126, CEN1074, CEN162, CEN1071, CEN289, CEN1079, CEN1075, CEN1073 and CEN161 were grouped (group 2) with the control. None of the tested isolates impaired seedling development when compared to the control.

The results obtained corroborate most studies with this group of fungi, using several agricultural species, in which increments in the treated plants were demonstrated, varying according to the isolate and plant studied, in the same way as was described by Tucci et al. (2011). These authors showed that the beneficial effect of Trichoderma isolates is modulated by the plant's genotype and, in some cases, it can be neutral or even harmful. With regard to positive results, studies conducted with tomato plants conducted by Azarmi et al. (2011), isolates from Trichoderma sp. and T. harzianum led to an increase in root and shoot weight, in agreement with what was verified in the present study. In the same sense, Mwangi et al. (2011) and Uddin et al. (2018) reported that treatments with T. harzianum promoted the growth of tomato plants, even in the presence of pathogens.

\subsection{Evaluation of Trichoderma Isolates for Rhizocompetence for Tomato Plants Under Greenhouse Conditions}

The 12 Trichoderma isolates used in the test were able to colonize the rhizosphere, and six of them colonized the rhizoplane (Table 5). According to Table 5, the data obtained with one isolate (CEN281) did not differ significantly from those verified with the control treatment based on the 5\% Tukey test. The CEN1076 isolate (group 2) deserves to be highlighted, as it presented a greater number of conidia per gram of root, thus indicating a high capacity to colonize the rhizosphere of the tomato. Seven isolates were not recovered in the platelets 
performed at $10^{-4}$ dilution, which does not mean, however, that these isolates were unable to colonize the rhizosphere of the plants.

Table 5. Grouping of Trichoderma isolates in terms of dry weight of tomato seedling root and comparison in terms of rhizocompetence (number of conidia per gram of root, 20 days after inoculation) in tomato, under the influence of seed treatment with fungus, based on the avarage length method of the Silhouette

\begin{tabular}{|c|c|c|c|c|c|c|}
\hline \multirow{2}{*}{ Strain } & \multicolumn{3}{|c|}{ Dry root weight } & \multicolumn{3}{|c|}{ Rhizocompetence } \\
\hline & Group & Weight in grams & Silhouette Validation & Group & Number of conidia $\times 10^{4} /$ gram of root & Silhouette Validation \\
\hline CEN1070 & 1 & $0.05 \pm 0.02 *$ & 0.65 & 1 & $18.53 \pm 8.08 *$ & 0.64 \\
\hline CEN1071 & 2 & $0.03 \pm 0.01$ & 0.64 & 1 & $18.53 \pm 8.08$ & 0.64 \\
\hline CEN1072 & 1 & $0.05 \pm 0.02$ & 0.65 & 1 & $18.53 \pm 8.08$ & 0.64 \\
\hline CEN1073 & 2 & $0.03 \pm 0.01$ & 0.64 & 1 & $18.53 \pm 8.08$ & 0.64 \\
\hline CEN1074 & 2 & $0.03 \pm 0.01$ & 0.64 & 1 & $18.53 \pm 8.08$ & 0.64 \\
\hline CEN1075 & 2 & $0.03 \pm 0.01$ & 0.64 & - & - & - \\
\hline CEN1076 & 1 & $0.05 \pm 0.02$ & 0.83 & 2 & $44.00 \pm 3.85$ & 0.92 \\
\hline CEN1077 & 1 & $0.05 \pm 0.02$ & 0.83 & 1 & $18.53 \pm 8.08$ & 0.64 \\
\hline CEN1078 & 2 & $0.03 \pm 0.01$ & 0.64 & 1 & $18.53 \pm 8.08$ & 0.64 \\
\hline CEN1079 & 2 & $0.03 \pm 0.01$ & 0.64 & 1 & $18.53 \pm 8.08$ & 0.64 \\
\hline CEN1080 & 3 & $0.07 \pm 0.03$ & 0.96 & 1 & $18.53 \pm 8.08$ & 0.64 \\
\hline CEN155 & 3 & $0.07 \pm 0.03$ & 0.96 & - & - & - \\
\hline CEN161 & 2 & $0.03 \pm 0.01$ & 0.64 & - & - & - \\
\hline CEN162 & 2 & $0.03 \pm 0.01$ & 0.64 & - & - & - \\
\hline CEN201 & 1 & $0.05 \pm 0.02$ & 0.83 & - & - & - \\
\hline CEN219 & 1 & $0.05 \pm 0.02$ & 0.83 & - & - & - \\
\hline CEN281 & 1 & $0.05 \pm 0.02$ & 0.83 & 1 & $18.53 \pm 8.08$ & 0.64 \\
\hline CEN287 & 2 & $0.03 \pm 0.01$ & 0.64 & 1 & $18.53 \pm 8.08$ & 0.64 \\
\hline CEN289 & 2 & $0.03 \pm 0.01$ & 0.64 & - & - & - \\
\hline Testemunha & 2 & $0.03 \pm 0.01$ & 0.64 & NA & NA & NA \\
\hline
\end{tabular}

Note. * Mean and standard deviation.

The survival of Trichoderma in the soil and in the rhizosphere of peas and beans was reported about 40 years ago by Papavisas (1981). Six years later, Ahmad and Baker (1987), described T. harzianum's competence in colonizing the rhizosphere. Tsahouridou and Thanassoulopoulos (2002) reported the ability of T. konigii isolates to colonize tomato roots, which corroborates the results described here. According to Bennett and Whipps (2008), some isolates have greater ability to colonize the rhizosphere than others, as observed here for CEN1076, which stood out in the rhizocompetence test. The rhizosphere colonization by Trichoderma isolates has also been described by Harman et al. (2004).

\section{Conclusion}

None of the tested Trichoderma isolates interfered negatively in the germination of tomato seeds and in the root development of seedlings, nor in the promotion of tomato growth. In some cases, an increase was observed in the weight of the root and aerial part of the plants. However, certain isolates can cause damage to tomato seedlings during the germination process, under high humidity conditions and absence of organic substrate. All isolates selected for the rhizocompetence test demonstrated the ability to colonize the rhizosphere of tomato plants in a greenhouse, with some also colonizing the rhizoplane. Thus, isolates selected in this work have potential as growth promoters and development of tomato plants.

\section{References}

Ahmad, J. S., \& Baker, R. (1987). Rhizosphere competence of Trichoderma harzianum. Phytopathol., 77(2), 182-189. https://doi.org/10.1094/Phyto-77-182

Azarmi, R., Hajieghrari, B., \& Giglou, A. (2011). Effect of Trichoderma isolates on tomato seedling growth response and nutrient uptake. Afr. J. Biotechnol., 10(31), 5850-5855. https://doi.org/10.5897/AJB10.1600

Baker, K. F., \& Cook, R. J. (1974). Biological control of plant pathogens (p. 433). San Francisco: W.F. Freeman. 
Bennett, A. J., \& Whipps, J. M. (2008). Dual application of beneficial microorganisms to seed during drum priming. Appl Soil Ecol., 38, 83-89. https://doi.org/10.1016/j.apsoil.2007.08.001

Bennett, A. J., Mead, A., \& Whipps, J. M. (2009). Performance of carrot and onion seed primed with beneficial microorganisms in glasshouse and field trials. Biol. Control., 51, 417-426. https://doi.org/10.1016/ j.biocontrol.2009.08.001

Dhingra, O. D., \& Sinclair, J. B. (1985). Basic Plant Pathology Methods. CRC Press, Florida.

Druzhinina, I. S., Seidl-Seiboth, V., Herrera-Estrella, A., Horwitz, B. A., Kenerley, C. M., Monte, E., ... Kubicek, C. P. (2011). Trichoderma: The genomics of opportunistic success. Nat. Rev. Microbiol., 9, 749-759. https://doi.org/10.1038/nrmicro2637

Elias, L. M., Domingues, M. V. P. F., Moura, K. E., Salomão, D., Harakava, R., \& Patricio, F. R. A. (2016). Selection of Trichoderma isolates for biological control of Sclerotinia minor and S. sclerotiorum in lettuce. Summa Phytopathol., 2(3), 216-221. https://doi.org/10.1590/0100-5405/2147

Ethur, L. Z., Lupatini, M., Blume, E., Muniz, M. F. B., Antoniolli, Z. I., \& Lorentz, L. H. (2012). Trichoderma asperellum na produção de mudas contra a fusariose do pepineiro. Sci. Agrar. Paran., 11(4), 73-84. https://doi.org/10.18188/sap.v11i4.5347

Ethur, L. Z., Marlove, M., \& Silva, A. C. F. (2006). Sanidade de sementes e emergência de plantulas de nabo forrageiro, aveia preta e centeio submetidas a tratamentos com bioprotetor e fungicida. Revista Ciência e Natura, 28(2), 17-27. https://doi.org/10.5902/2179460X9700

Hajieghrari, B. (2010). Effects of some Iranian Trichoderma isolates on maize seed germination and seedling vigor. Afr. J. Biotechnol., 9(28), 4342-4347.

Hajieghrari, B., \& Mohammadi, M. (2016). Growth-promoting activity of indigenous Trichoderma isolates on wheat seed germination, seedling growth and yield. Aust. J. Crop. Sci., 10(9), 1339-1347. https://doi.org/ 10.21475/ajcs.2016.10.09.p7857

Harman, G. E. (2011). Multifunctional fungal plant symbionts: New tools to enhance plant growth and productivity. New Phytologist., 189, 647-649. https://doi.org/10.1111/j.1469-8137.2010.03614.x

Harman, G. E., Howell, C. R., Viterbo, A., Chet, I., \& Lorito, M. (2004). Trichoderma species-opportunistic, avirulent plant symbionts. Nat. Rev., 2, 43-56. https://doi.org/10.1038/nrmicro797

IBGE (Brazilian Institute of Geography and Statistics). (2020). Systematic Survey of Agricultural Production, July 2020. Retrieved from https://sidra.ibge.gov.br/home/lspa/brasil

Islam, M. S., Rahman, M. A., Bulbul, S. H., \& Alam, M. F. (2011). Effect of Trichoderma on seed germination and seedling parameters in chili. Int. J. Expt. Agric., 2(1), 21-26. https://doi.org/10.3329/jsf.v8i1-2.14637

Islam, M., Hossain, D. M., Nonaka, M., \& Harada, N. (2016). Biological control of tomato collar rot induced by Sclerotium rolfsii using Trichoderma species isolated in Bangladesh. Arch. Phytopathology Plant Protect., 50(3-4), 1-9. https://doi.org/10.1080/03235408.2016.1265243

Kirk, P. (2012). Index Fungorum. CABI Bioscience, CBS and Landcare Resarch. Retrieved January 26, 2020, from http://www.indexfungorum.org/Names/Names.asp?strGenus=Trichoderma

Kleifeld, O., \& Chet, I. (1992). Trichoderma harzianum - Interaction with plants and effect on growth response. Plant and Soil, 144, 267-272. https://doi.org/10.1007/BF00012884

Mastouri, F., Björkman, T., \& Harman, G. E. (2010). Seed treatment with Trichoderma harzianum alleviates biotic, abiotic, and physiological stresses in germinating seeds and seedlings. Phytopathol., 100, 1213-1221. https://doi.org/10.1094/PHYTO-03-10-0091

Menzies, J. G. (1993). A strain of Trichoderma viride pathogenic to germinating seedlings of cucumber, paper and tomato. Plant Pathol., 42, 784-791. https://doi.org/10.1111/j.1365-3059.1993.tb01565.x

Mwangi, M. W., Monda, E. O., Okoth, S. A., \& Jefwa, J. M. (2011). Inoculation of tomato seedlings with Trichoderma harzianum and arbuscular mycorrhizal fungi and their effect on growth and control of wilt in tomato seedlings. Braz. J. Microbiol., 42(2), 508-13. https://doi.org/10.1590/S1517-83822011000200015

Nakagawa, J. (1999). Testes de vigor baseados no desempenho das plântulas. In F. C. Krzyzanowski, R. D. Vieira, \& J. B. França Neto (Eds.), Vigor de sementes: Conceitos e testes (Cap. 2, pp. 1-24). Londrina: Abrates. 
Ousley, M. A., Lynch, J. M., \& Whipps, J. M. (1993). Effect of Trichoderma on plant-growth-A balance between inhibition and growth promotion. Microb. Ecol., 26, 277-285. https://doi.org/10.1007/BF00176959

Papavizas, G. V. (1981). Survival of Trichoderma harzianum in soil and in pea and bean rhizospheres. Phytopathol., 72, 121-125. https://doi.org/10.1094/Phyto-72-121

Rousseeuw, P. J. (1987). Silhouettes: A graphical aid to the interpretation and validation of cluster analysis. $J$. Comput. Appl. Math., 20, 53-65. https://doi.org/10.1016/0377-0427(87)90125-7

Sandheep, A. R., Asok, A. K., \& Jishha, M. S. (2013). Combined inoculation of Pseudomonas fluorescens and Trichoderma harzianum for enhancing plant growth of vanilla (Vanilla phanifolia). Pak. J. Biol. Sci., 16(2), 580-584. https://doi.org/10.3923/pjbs.2013.580.584

Stewart, A., \& Hill, R. (2014). Applications of Trichoderma in Plant Growth Promotion. Biotechnology and Biology of Trichoderma. Biotechnology and Biology of Trichoderma (pp. 415-428). Elsevier: New Zealand. https://doi.org/10.1016/B978-0-444-59576-8.00031-X

Tsahouridou, P. C., \& Thanassoulopoulos, C. C. (2002). Proliferation of Trichoderma konigii in the tomato rhizosfhere and the suppression of danping-off by Sclerotium rolfsii. Soil Biol. Biochem., 34, 767-776. https://doi.org/10.1016/S0038-0717(02)00006-8

Tucci, M., Ruocco, M., De Masi, L., De Palma, M., \& Lorito, M. (2011). The beneficial effect of Trichoderma spp. on tomato is modulated by the plant genotype. Mol. Plant Pathol., 12(4), 341-54. https://doi.org/ 10.1111/j.1364-3703.2010.00674.x

Uddin, M. N., Rahman, U., Khan, W., Uddin, N., \& Muhammad, M. (2018). Effect of Trichoderma harzianum on tomato plant growth and its antagonistic activity against Pythium ultimum and Phytophthora capsici. Egypt. J. Biol. Pest Control, 28, 32. https://doi.org/10.1186/s41938-018-0032-5

Vitti, A., Monaca, E., Sofo, A., Scopa, A., \& Cuypers, M. N. (2015). Beneficial effects of Trichoderma harzianum T-22 in tomato seedlings infected by Cucumber mosaic virus (CMV). BioControl, 60, 135-147. https://doi.org/10.1007/s10526-014-9626-3

Zilli, J. E., Hungria, M., Soares, L. H., Mello, S. C. M., Oliveria, C. A., Castro, M. E., ... Klein, C. S. (2019). Recursos Genéticos Microbianos. In S. R. Paiva, M. Albuquerque, D. Dslomão, A. Nassif, S. C. B. Roveri, \& J. R. Moreira (Eds.), Recursos Genéticos: O produtor Pergunta, a Embrapa Responde (p. 298). Brasília, DF. Retrieved from https://www.infoteca.cnptia.embrapa.br/infoteca/handle/doc/1113671

\section{Copyrights}

Copyright for this article is retained by the author(s), with first publication rights granted to the journal.

This is an open-access article distributed under the terms and conditions of the Creative Commons Attribution license (http://creativecommons.org/licenses/by/4.0/). 